\title{
OSCILLATION ANALYSIS FOR NONLINEAR NEUTRAL DIFFERENTIAL EQUATIONS OF SECOND ORDER WITH SEVERAL DELAYS AND FORCING TERM
}

\author{
SHYAM SUNDAR SANTRA
}

\begin{abstract}
In this paper, sufficient conditions are obtained for the oscillation of the nonlinear neutral forced differential equations of second-order with several delays of the form
\end{abstract}

$(E)$

$$
\frac{\mathrm{d}}{\mathrm{d} t}\left[r(t) \frac{\mathrm{d}}{\mathrm{d} t}[x(t)+p(t) x(t-\tau)]\right]+\sum_{i=1}^{m} q_{i}(t) H\left(x\left(t-\sigma_{i}\right)\right)=f(t), \quad t \geq t_{0}>0,
$$

under the assumptions $\int^{\infty} \frac{1}{r(\eta)} \mathrm{d} \eta=\infty$ and $\int^{\infty} \frac{1}{r(\eta)} \mathrm{d} \eta<\infty$ for various ranges of the bounded neutral coefficient $p$. Also, an attempt is made to discuss existence of bounded positive solutions of $(E)$. Further, one illustrative example showing the applicability of the new results is included.

MSC 2010. 34C10, 34C15, 34K 40.

Key words. Contraction principle, delay, existence of positive solution, neutral differential equations, non-linear, nonoscillation, oscillation.

\section{REFERENCES}

[1] B. Baculikova, T. Li and J. Dzurina, Oscillation theorems for second order neutral differential equations, Electron. J. Qual. Theory Differ. Equ., 74 (2011), 1-13.

[2] J. Dzurina, Oscillation theorems for second order advanced neutral differential equations, Tatra Mt. Math. Publ., 48 (2011), 61-71.

[3] I. Gyori and G. Ladas, Oscillation Theory of Delay Differential Equations with Applications, Clarendon Press, Oxford, 1991.

[4] T.H. Hilderbrandt, Introduction to the Theory of Integration, Pure and Applied Mathematics, Academic Press, Vol. 13, New York, 1963.

[5] H.K. Hale, Theory of Functional Differential Equations, Spinger, New York, 1977.

[6] M. Hasanbulli and Y.V. Rogovchenko, Oscillation criteria for second order nonlinear neutral differential equations, Appl. Math. Comput., 215 (2010), 4392-4399.

[7] J. Jiang and X. Li, Oscillation of second order nonlinear neutral differential equations, Appl. Math. Comput., 135 (2003), 531-540.

This work is supported by the Department of Science and Technology (DST), New Delhi, India, through the bank instruction order No. DST/INSPIRE Fellowship/2014/140 (dated Sept. 15, 2014).

DOI: $10.24193 /$ mathcluj.2019.1.06 
[8] B. Karpuz and S.S. Santra, Oscillation theorems for second-order nonlinear delay differential equations of neutral type, Hacet. J. Math. Stat., DOI:10.15672/HJMS.2017.542, in press.

[9] H.J. Li, Oscillation of solutions of second-order neutral delay differential equations with integrable coefficients, Mathematical and Computer Modelling, 25 (1997), 69-79.

[10] T. Li and Rogovchenko, Y.V., Oscillation theorems for second-order nonlinear neutral delay differential equations, Abstr. Appl. Anal., 2014, Article 594190, 1-5.

[11] Q. Li, R. Wang, F. Chen and T. Li, Oscillation of second-order nonlinear delay differential equations with nonpositive neutral coefficients, Adv. Difference Equ., 2015, Article $35,1-7$.

[12] X. Lin, Osillation of second-order nonlinear neutral differential equations, J. Math. Anal. Appl., 309 (2005), 442-452.

[13] Q. Meng and J. Yan, Bounded oscillation for second order non-linear neutral delay differential equations in critical and non-critical cases, Nonlinear Anal., 64 (2006), 15431561.

[14] S. Pinelas and S.S. Santra, Necessary and sufficient condition for oscillation of nonlinear neutral first-order differential equations with several delays, J. Fixed Point Theory Appl., 20 (2018), Article 27, 1-13.

[15] W. Shi and P. Wang, Oscillatory criteria of a class of second-order neutral functional differential equations, Appl. Math. Comput., 146 (2003), 211-226.

[16] S.S. Santra, Oscillation criteria for nonlinear neutral differential equations of first order with several delays, Mathematica, 57 (80) (2015), 75-89.

[17] S.S. Santra, Necessary and sufficient condition for oscillation of nonlinear neutral first order differential equations with several delays, Mathematica, 58 (81) (2016), 85-94.

[18] S.S. Santra, Oscillation analysis for nonlinear neutral differential equations of second order with several delays, Mathematica, 59 (82) (2017), 111-123.

[19] J. Wong, Necessary and sufficient conditions for oscillation of second-order neutral differential equations, J. Math. Anal. Appl., 252 (2000), 342-352.

[20] P. Wang, Oscillation criteria for second-order neutral equations with distributed deviating arguments, J. Comput. Appl. Math., 47 (2004), 1935-1946.

[21] R. Xu and F. Meng, Some new oscillation criteria for second order quasilinear neutral delay differential equations, Appl. Math. Comput., 182 (2006), 797-803.

[22] Z. Xu and P. Weng, Oscillation of second order neutral equations with distributed deviating argument, J. Comput. Appl. Math., 202 (2007), 460-477.

[23] Q. Yang, L. Yang and S. Zhu, Interval criteria for oscillation of second-order nonlinear neutral differential Equations, Comput. Math. Appl., 46 (2003), 903-918.

Received March 26, 2018

Accepted May 22, 2018

\author{
Sambalpur University \\ Department of Mathematics \\ Sambalpur 768019, India \\ E-mail: shyam01.math@gmail.com
}

